\title{
A Rotation in Contemporary Legal Scholarship
}

\section{Citation}

David W. Kennedy, A Rotation in Contemporary Legal Scholarship, 12 Ger. L.J. 338 (2011).

\section{Published Version}

http://www.germanlawjournal.com/pdfs/Vol12-No1/

PDF_Vol_12_No_01_338-375_Articles_David_Kennedy.pdf;http://www.germanlawjournal.com/ index.php?pageI $\bar{D}=11$ \&artI $\mathrm{D}=1323$

\section{Permanent link}

http://nrs.harvard.edu/urn-3:HUL.InstRepos:11222699

\section{Terms of Use}

This article was downloaded from Harvard University's DASH repository, and is made available under the terms and conditions applicable to Open Access Policy Articles, as set forth at http:// nrs.harvard.edu/urn-3:HUL.InstRepos:dash.current.terms-of-use\#OAP

\section{Share Your Story}

The Harvard community has made this article openly available.

Please share how this access benefits you. Submit a story.

Accessibility 


\title{
Articles
}

\section{A Rotation in Contemporary Legal Scholarship}

\author{
By David Kennedy ${ }^{*+}$
}

\section{A. Introduction}

I develop my picture of contemporary legal scholarship in two broad strokes. In the first section, I focus on the relationship between legal scholarship and the traditions of theory, philosophy, and the human sciences, arguing that the interdisciplinary work of contemporary legal scholarship expresses legal culture's uneasiness about intellection. In the second section, I focus on the relationship between legal scholarship and political engagement, arguing that the programatic or exhortatory tone, structure and context of contemporary legal scholarship expresses legal culture's uneasiness about what it thinks of as "politics".

My picture, then, is of a legal academy defined by two broad anxieties. What, we wonder, is our relationship to thought and action? The North American legal scholar seems simultaneously preoccupied with and mistrustful of both thinking and doing. In this essay, I argue that recent changes in North American legal scholarship represent rotations in the legal academic's experience of this problematic, with differences among various scholarly strands marked by contrasting responses to this double uneasiness. In particular, the recent development of critical scholarship on both the left ("CLS") and right ("law and economics") in the United States might be understood as accommodations of this common difficulty. This suggests a continuity in contemporary legal scholarship stronger than academics of these strands generally assert.

\footnotetext{
* Professor of Law and Faculty Director of the Institute for Global Law and Policy at Harvard Law School. He teaches international law, international economic policy, legal theory, law and development and European law. He holds a Ph.D. from the Fletcher School at Tufts University and a J.D. from Harvard. He is the author of numerous articles on international law and global governance. His research uses interdisciplinary materials from sociology and social theory, economics and history to explore issues of global governance, development policy and the nature of professional expertise. He has been particularly committed to developing new voices from the third world and among women in international affairs. As a practicing lawyer, Kennedy has worked on numerous international projects, both commercial and public, including work with the United Nations, the Commission of the European Union, and with the private firm of Clearly, Gottlieb, Steen and Hamilton in Brussels, where his work combined European antitrust litigation, government relations advising and general corporate law. A member of the US Council on Foreign Relations, he serves as Chair of the World Economic Forum's Global Advisory Council on Global Governance. Email: dkennedy@law.harvard.edu

${ }^{+}$Back in 1986-88 readers of this contribution could be expected to be aware of the "contemporary legal scholarship" which is sketched out in this article. Today a lot of footnotes would be necessary to make the many references to - then - ongoing debates more transparent. We have decided, however, not to change the original and to thus impart some flavor of the 80ies.
} 
I am particularly concerned with two broad transitions in legal scholarship over the last fifteen years or so: first the development of a harsh challenge to "traditional" or "mainstream" scholarship represented by the self-conscious "schools" of legal scholarship now known as "law and economics" and "CLS" or "CLS". These schools proclaim both their distinctiveness and their critical ambitions more assertively than do the various strands of the mainstream to which they respond, whether these be known by some moniker ("legal process", "law and society", "law and literature", etc.) or simply as "legal scholarship". Legal scholarship which breaks with the mainstream, whether of the right, left or center, marks its departure in part by shifting interdisciplinary associations (importing theories of interpretation, moral philosophy, economics or post-structuralist criticism to legal scholarship) and in part by altering their political program.

Second, I am interested in the developments within left, and, to lesser extent, right and "mainstream" scholarship which have occurred as these challenges matured and began taking account of one another. Both CLS and law and economics - like the mainstream "law and literature" movement - have experienced second or third generation struggles and transitions since first breaking loose from the mainstream. Although the scholarship of each school developed in part through substantive discussions of particular doctrinal or methodological or institutional issues, these struggles were also importantly marked by alterations in participating legal scholars' accommodative strategies to the common anxieties about thinking and doing, by shifts in interdisciplinary strategies and tonal polemics.

In this essay, I have focused most intensely on the development of "CLS" scholarship, in part because I am most familiar with that history and in part because the Bremen Conference was primarily interesting as an exchange between legal scholars of the "left". In looking at left legal scholarship, I am most interested in the relationship between work produced during the first wave of the CLS movement during the 1970s and work produced more recently, in part by an academic generation who studied under both mainstream and CLS scholars, a generation which sees its work as a response to both and often writes in the argot of "post-modernism", "post-structuralism", or "feminism". This transition, like the initiating break with the mainstream, has been marked by a shift in both interdisciplinary associations and political style.

I should say a word about my use of the word "mainstream". In terming "CLS" "left" or "law and economics" "right", I have simply adopted the self-proclaimed positions of scholars producing work in each school. Although these characterizations might well be challenged - and indeed the politics of "left" and "right" scholarship could bear closer scrutiny - they would likely be accepted by those most closely identified with each school. In any case, I feel comfortable dropping the quotation marks.

The term "mainstream" is an entirely different matter. For one thing, mainstreamers' uneasiness about their relationship to intellection and politics expresses itself as a distaste 
for labels of any but the most benign descriptive and depoliticized sort - referring vaguely to method ("law and literature") or doctrinal orientation ("legal process"). They like to reserve political labels like "right" or "left" for private convictions and would resist both applying political labels to legal scholarship and appropriating labels they feel proud to acknowledge outside the context of their scholarly work. Most importantly, moreover, mainstream scholarship is in many ways more diverse than either of the schools which respond to it. Indeed, it constitutes a single strand only as it has been responded to as such - and perhaps only in the imagination of those making the response.

That said, I will retain the label, for the mainstream does seem to relate in a singular fashion to the problematic I am most concerned about in this essay - the tangled relationship between scholarship on the one hand and intellection or politics on the other. The mainstream scholar I have in mind has dominated the North American legal academy at least since the fifties, but is probably most often associated with the Great Society, itself a high water mark of liberalism in legal thought. Mainstream liberals have participated in the changes of intellectual focus and political tone of the seventies and eighties without altering their political or theoretical orientation.

\section{B. Legal Scholars and the World of Ideas}

Legal scholars have an uneasy relationship to the literatures of philosophy, political theory, literary criticism, history, sociology, economics - indeed to other disciplines generally. The mainstream scholar bears this uneasiness gracefully. Many of the extra-legal notions upon which he relies have been domesticated within legal theory or "jurisprudence" and his selfconscious eclecticism encourages a range of extra-legal borrowings. Nevertheless, the relationship between the core of mainstream doctrinal elaboration, analysis and advocacy and the periphery of legal theory, policy and interdisciplinary work of various sorts remains an anxious one.

To an extent this is simply the uneasiness of our common profession. Law teachers are both lawyers and academics, straddling the worlds of commerce and thought. We are often paid more than our colleagues in other academic departments and less than our classmates in practice. We wonder whether we might not more consistently have lived out the logic of one or the other of our identities. At the same time, all who engage in the elaboration and defense of legal academia participate in legal culture's general uneasiness about ideas. On the one hand, law and legal academia present themselves as humbly disconnected from high (and perhaps irrelevant or effete) culture. Law is street smart rather than scholarly. At the same time, however, both legal culture and legal academia, present themselves as the embodiment of a moral culture above, or removed from the complex difficulties of the human sciences. Propositions of morality, intention and the general good which the philosopher might find platitudinous are straightforwardly 
asserted and confidently defended within legal culture. In this, law carries culture above the controversies of nit-picking academics.

Much might be and has been made about law's fascination with and uneasiness about intellection. For example, we might read the law's discomfort with - even exclusion of intuition, philosophy, religion or mysticism, as an expression of legal culture's misogynist, homophobic or anti-semitic imagination. We might read law's preoccupation with its own reason as a colonial extension of Northern industrial protestantism. Law's fascination with high culture might be read as the arrogant pretension of a monopolizing profession - our participation in the historical turn to positivism and science associated in the U.S. with every move from commerce to professional status.

However we read it, the law and the legal academic express their troubled relationship to the intellectual in myriad ways: in the historically parallel consolidation of the legal profession and academy, in the demands which legal argument has made since the collapse of formalism for interdisciplinary borrowings, and in the pressures which the rituals of legal publication and academic promotion exert for conspicuous erudition, and more. As a first step, we might read legal culture's subtle obsession with the boundaries between law and everything else or between legal theory and legal practice as indicia of this troubled relationship. And these boundary concerns structure both our professional culture and our doctrinal or scholarly work.

On the professional side, we see it in the complex relationships between legal faculties and the world of practice, or, more immediately, within faculties between those who earn their respect by venerating or by disdaining legal practice. It is not surprising that both left and right began their challenges to the mainstream by calling: I am theory and you are practice, for these are the professional divisions most readily available to practitioners of academic politics. In our discipline, critique begins the project of self-definition by challenging the purity of either the theory or the practice of the mainstream. But soon the distinction reappeared within both critical movements and relations with the mainstream became more complex, for legal scholarship is self-consciously both theory and practice in all of its manifestations.

On the side of doctrine and scholarship, we see this troubled and doubled connection to thought in the academy's oscillation between assertions of its insightful specialness and its aw shucks humble pie. Jurisprudential schools and tendencies distinguish themselves by touting either the law's unique reason - in the hermetics of legal process or the wisdom of "thinking like a lawyer" - or its intimate connection with the traditions of literature, sociology and policy science. Doctrines repeat this distinction between the knowledges of law and life - in their endless respect for the differences between public and private, objective and subjective, substance and process, interpretation and application, law and facts, legislative and judicial, etc. 
In this section, I pursue the traces of this double uneasiness through the scholarly work of the mainstream and the development of a left response. Doing so requires that we recall the stability of mainstream liberalism in legal scholarship - heir to the legal realism of the nineteen twenties and thirties - in both its more complacent fifties and critical sixties manifestations.

\section{Mainstream eclecticism}

Few in the legal academy would dispute that legal theory has become more sophisticated and the methods of legal scholarship more eclectic since the interwar era of "legal realism". Realism set in motion changes which have defined the post-war generation of legal mainstream academics and which have highlighted the relationships between law and other disciplines. One striking manifestation of this development is that one can hardly peruse a law journal without encountering references to what once seemed the obscure texts of divergent disciplines, for interdisciplinary nourishment has become a staple part of the post-realist mainstream.

Most agree that the realists left legal scholarship in a real quandary. One way to think about realism's legacy for North American legal scholarship is to focus on two scholarly inquiries which have seemed, since realism, increasingly difficult to pursue. First, what makes law special, independent, autonomous? Second, what gives law its force, or bite, or connection to social life? The realists, by demonstrating the mutual implication of law and political or social life, made it more difficult to account for law's autonomy. At the same time, their insights into the extremely flexible relationship between given legal propositions and particular social relations made it more difficult to explain law's normative bite. Thinking about realism in this way, as a simultaneous challenge to the independence and force of law, illuminates the post-realist's difficult relationship to the worlds of both thought and power. In short, the mainstream legal scholar repeats in his uneasy relationship to both other disciplines and to politics his anxiety about the independence and authority of law - and the legal academic.

As the realists' insights have been developed over the past decades, becoming ever more culturally pervasive, legal theory and doctrine have come to seem weaker and less persuasive. Doctrinal argument seems increasingly complex and ever less able to determine outcomes. The normative moorings of the most basic doctrinal discourse by lawyers, scholars and judges seem infirm. Legal principles, rules and policy arguments seem to dissolve far too easily into thin disguises for assertions of interest. The more diverse the sphere of an argument's application, the thinner it seems to become until its manipulability becomes more apparent than its persuasive clout. The result has been ever more polarized arguments, ever more sophisticated doctrinal diversity, and ever more narrowly applicable holdings. 
At the same time, legal theory seems both bogged down in controversy and increasingly irrelevant to the work of legal practice. Descriptions and analyses of doctrinal developments have been unable to explain the unstructured and diverse nature of contemporary law without either abandoning the idea of a normative law or limiting the ambit of normative claims to a few fairly narrow cases. Theoreticians have been unable to describe what goes on in post-realist legal culture without choosing between a defense of law's normative claims which abandons a great deal of the field occupied by lawyers to politics and a defense of law's scope which abandons claims about its special normative status.

Bluntly put, after realism, there was no generally accepted sense in the American legal academy about what makes law distinctive and how law can be stably linked to social behavior. But these remained the questions. Far from becoming discouraged, legal scholars seemed to become obsessed with figuring out what law is and what gives law normative stability. And there were nearly as many answers as there were legal scholars.

Moreover, faced with the growing fragmentation of legal theory and doctrine, lawyers scavenged in foreign disciplines, rushing to the bookstore to shore up their own edifice. This has worked in a couple of different ways, in part depending upon the question which seemed most pressing. Sometimes, particularly when focusing on the question of law's stable bite, disciplines such as sociology, history, political science and economics have been used to provide a structured (even a legally structured) base for or alternative to the increasing fragmentation of the law. This approach makes it difficult to explain law's distinctiveness. Typically, the scholar tries to account for law's identity by claiming that the things legal people do are, or are structured by, or contribute to, a legal process - for even if everything is political, it is not, after all, just politics. This very practical, practice oriented approach, threatens to be very uncritical. In an extreme form, it tends towards the tautological - law, however like everything else it seems, is the realm of the legal.

On the other hand, particularly when the issue of law's autonomy seemed most pressing, mainstream scholars have relied on disciplines such as philosophy, moral theory or literary theory to assert that law exists and works when it is good, followed and understood. Needless to say, this internal focus on legal culture - even law as culture - makes it difficult to explain law's authority or stable bite and seems equally prone to the tautological. But we already see an important structure. Other disciplines are invited into legal scholarship to resolve different questions - questions which together, when posed simultaneously to the same discipline, seem impossible to answer. The result is an odd division of intellectual labor - for law's independence, see philosophy, for law's authority, see political science.

Either of these strategies alone, of course, would merely restate the problem posed by realism: how to account for law's scope without reducing its power in a culture skeptical of both natural law and science. But the particulars of these strategies are less important than the collective impression they leave. Suddenly fragmentation is a virtue rather than a 
vice. And post-realist legal scholars have responded to the doubts raised by realism with eclectic proliferation: more articles, more references, more diverse arguments, drawing simultaneously on as many disciplines as possible.

Their strength comes not solely from the sheer weight of their output, however, but from the shrewd shuttleplay between skepticism and reconstruction which this interdisciplinary profusion makes possible. Neither an economic/political account of a legal process enmeshed in a world of interests nor a philosophical/moral account of legal teleology isolated in a world of transactions is very satisfying. But maneuvering between them, and restating their difference in a thousand subtle nooks and crannies is more than satisfying it is a productive scholarly industry.

Despite this strength, however, it is easy to imagine how a proliferation of complexly strategized ambiguity and paradox about law's relationship to the human and social sciences might make mainstream legal academics uneasy. At a first level, it is easy to see that reliance upon political science or moral philosophy seems unlikely to respond to realist fueled disintegration. After all, it was insights about the unavoidable implication of politics and morality in the law which fueled legal realism in the first place. It seems unlikely that distinctions which are obviously unworkable within legal culture will prove very satisfying when transformed into boundaries between law and its sister disciplines.

Nevertheless, this interdisciplinary strategy has a familiar and persuasive structure denying abroad what we know to be true at home. Reference to foreign disciplines allows us to forget our realism - realism is our problem, a dirty little secret. At the same time, this strategy is plagued by a familiar uneasiness. What if they find out? What if their disciplines are no more firmly structured than our own? And anyway, isn't it our realism that makes us special, sophisticated, shrewd? Despite his aspiration to transcend realism by roaming the library, the mainstream legal scholar finds himself nagged by its shadow.

Moreover, this shadow became ever more prominent, for mainstream legal scholars were quick to deploy the insights of realism against one another. If the practice of scholarly elaboration was the suppression of realism beneath eclectic interdisciplinary promises, the practice of academic criticism came to be the deployment of realist insights against precisely such reconstructions. As one after another human science was deployed in legal scholarship, criticism extended and deepened realism's shadow, fueling the very fragmentation all this production sought to calm. Slowly, every post-realist came to seem the last honest man, untainted by fragmentation. I judge, therefore I am.

But the uneasiness of mainstream legal scholars about interdisciplinary work has another, more personal source. Exactly as fragmentation heightened each scholar's isolation, the solidity of his professional identity was coming unstuck. The more they retooled the less able they seemed to communicate with one another. Moreover, being an interdisciplinary traveler exacts a toll. Traversing foreign terrain - whether as a legal comparativist or 
methodological eclectic - is troubling in a couple of ways. If undertaken to enrich the law, the project threatens the scholar's loyalty to his own discipline. One ponders the advantages of going native, renouncing professional fealty, becoming an historian, economist, philosopher.

To the extent the scholar remains loyal to the law, he worries both that he will never fully enter and understand the foreign discipline and that his attachment to it will render him professionally marginal, dependent upon the fickle import trade in functionally applicable insights. How long will legal scholars find psychiatry fascinating? Aren't they already beginning to prefer sociology? In this sense the eclectic seems actually to relive law's uneasiness about its relationship to the rest of life, enacting the theoretical doubts which realism generated and which his eclecticism is meant to address.

Despite these difficulties, post realist legal culture seems by and large to have been sustained rather than sabotaged by their complex relationship to the world of ideas. Although it seems that the eclectic might be consumed, professionally and theoretically torn apart, by the doubts which law raises about intellectual culture and which interdisciplinary roaming raises about legal culture, it has not worked out this way. Instead, post-realist legal scholars have marked their difference from realism - their distance from its disintegrating insights - in their distinctive management of interdisciplinary roaming.

Let me pause for a moment on this notion of management, for it seems the secret of much contemporary legal work. My sense is of a scholarly community, perhaps an industry, sustained not by a shared sense of problems to be addressed or criteria for evaluating resolution, but rather by a collective practice of shrewd equivocation, by which every attempt at problem definition or resolution is transformed into a process, perhaps an institution, of evocation, deferral and repetition. Interdisciplinary roaming seems but one example of this practice, an example which institutionalizes the legal academic's unsettled sensibility about ideas.

A typical post-realist work of legal scholarship might refer the reader seeking authority and resolution for thorny problems to the worlds of practice (known by sociology), judicial decision (known by literary interpretation and linguistics), legislative fiat (known by political science), moral judgment (known by philosophy), business practice (known by empirical study) or market efficiency (known by economics). The key to such referrals is their solidity. The realm to which reference is made is projected far more stably than it might appear to scholars tilling its fields. Thus, the insistent call for careful empirical study or philosophical reflection imagines a stable practice known only as a hope - just as nostalgia for a once and future business judgment, market efficiency or procedural imperative invokes a meaningfulness sustainable only as a memory.

For this to work, the imports must be crude - must compensate for the sophistication of the realist's critique of law's independence and authority. It is difficult at first to see how 
such crude imported references could do the job - especially in the face of shrewd collegial critique. One partial explanation might be provided by the mainstream post-realist's relationship to his own practice, for the typical post-realist legal scholar devotes a significant part of his time to the "practice" of generating imperatives of the sort he can invoke in his scholarly work.

He might work with the profession, codifying, restating and cataloging norms, with the professional representing the judgments of business, with the poor, experiencing the imperatives of politics, or with the government, developing the necessities of institutional process. Or he might work with the sociologists doing empirical work, with the economists generating and testing models, and so forth. Whatever he does when he is not teaching or writing he remembers in his scholarship more nobly, more insistently, more clearly, more hopefully, than he admits in conversation. Thus we might think of the post realist scholar writing about doctrine this way: suddenly, if repeatedly, he stumbles on difficulties of fragmentation, undecidability and uncertainty, and he invokes another discipline, remembering - himself, on another day, in another mood, steadfast.

In this way, the interdisciplinary practice and scholarship of the typical post-realist reinforce one another. The sophistication of the practice - its imbedded uncertainty - is buttressed by the clarity of the scholarly narrative. If the practice seems crude, the scholarship is tenuous, delicate, finely nuanced and open-ended. When the scholarship seems fragmented, it remembers the practice, and so on. All these references back and forth across the boundary between thinking and doing, between a rejection and a transcendence of intellection, when things go right, give post-realist work a positive forward spin.

It is important to realize, however, that it is the work, the judgment, which seems authoritative, confident. The mainstream legal scholar himself seems lost. For all the elaborate self-reference of much post-realist legal writing, this delicate textual management is usually marked by a distinctively self-effacing tone and purport. Interdisciplinary travels have eroded the assertiveness of the legal writer - his willingness to speak as the embodiment of a self-confident legal culture. Conflicts about identity and loyalty do that - and in any case some such erosion seems to have sparked the flight to foreign terrain in the first place. As a result, the modern legal voice is strangely flat and disembodied - assertive only about its humility and the difficulty of its enterprise. The unsatisfactory nature of each interdisciplinary movement is deployed to suggest the next. In this, the mainstream eclectic seems to have saved his field only by losing his voice.

\section{The mainstream critic}

Before turning to scholars - such as those associated with CLS or law and economics - who situate themselves against the mainstream, it is important to focus on the extent to which 
the mainstream legal scholar pursues a critical project despite the fact that the eclecticism of modern legal scholarship seems primarily a defense of law against the disintegration set in motion by the realists. Indeed, the post-realist seems as determined to extend realism's critical project as he is to respond to it. His difficulty is that the product of his eclectic construction is extremely difficult to undo. Shrewdly equivocal and passionately disengaged, the mainstream discourse of contemporary law is infuriatingly difficult to criticize. It is hardly surprising that the post-realist would be as rigorous in pillaging the terrain of modern thought for a telling critical vantage point as he was in the search for a workable, if temporary, Archimedean point.

Occasionally the post-realist produces an article which seems wholly critical in tone. More often, however, his criticism is woven subtly into an argument which is predominantly constructive in aim and tone. He criticizes other post-realists or dismisses propositions which lie outside or challenge his own reconstructive agenda in one way or another. He deploys criticism to clear the ground for his own reimaginative project. Although an integral part of the post-realist enterprise, however, this criticism seems uneasily restrained. Post-realist work typically relates to criticism much as it relates to intellection, managing and absorbing criticism - assertively, hesitantly, tentatively, at times almost flirtatiously.

One way to sort out this complicated interchange between reconstruction and criticism (or, if you prefer, between the rebuke and the revival of realism) in mainstream postrealist legal scholarship is to focus on the oscillation within these texts between norm and deed, theory and practice, prescription and description. This relationship is telling because the post-realist repeats in his scholarly differentiation of theory and practice his anxiety about his identity as law and his difference from intellection - or his force as judgment.

Let me pause here on this notion of repetition. My sense is that to develop a picture of the post-realist, a picture which can stabilize his shifting identity and uncertainty about thought, we might trace a set of relations which mirror our scholar's relationship to ideas. Even as the post-realist fudges the boundary between law and other disciplines, we find him emphasizing the relationships between legal practice and legal scholarship, theory and doctrine, the legal sub-cultures of objective and subjective legal cultures, and so on. I want to dwell for a moment on the relationship between two distinctions which loom large in the post-realist imagination - between theory and doctrine on the one hand, and criticism and construction on the other - to illustrate my sense of repetition. In seems, moreover, that the relationship between these distinctions is managed by maneuvering the boundary between law and other disciplines.

First, the distinction between theory and doctrine. Mainstream scholars seem to retain faith in the severability of doctrinal and theoretical tasks, usually seeking first to elaborate the system of norms and then to analyze the normative system which they have created. They speak with two voices, imagining themselves as both creator and consumer of the 
legal fabric. In "doing theory" they compare conceptions of law for their descriptive and prescriptive fit with the legal world - a comparison informed by various interdisciplinary images of that world. In doctrinal work, by contrast, they elaborate norms to cover new cases, clarify the interpretation of past situations and construct arguments to resolve contemporary disputes - again informed by a variety of extralegal methods and insights.

The post-realist pursues this double agenda partly out of a sense that legal theory and doctrine are richly textured and quasi-independent realms. The "quasi-independence" of theory and doctrine expresses their sense that something about the performance of one seems to preclude the performance of the other. Those engaged in the elaboration of legal rules and standards could be either descriptive or imaginative, but in either case, they seem unable to search simultaneously for the source or justification of the law they propound. In order to elaborate legal rules, to separate law and not law, one must first understand the difference between legal norms and other behavioral patterns. That much seems inherent in the definition of elaboration.

Likewise, to practice the scholarship of justifying or explaining the resulting system of laws from the remove of a theoretical perspective, one must begin with a vision of the corpus of law which needs explanation or justification. That much seems required by the nature of justification. The scholar may practice either elaboration or explanation, may combine the two in a single article, may recognize that in some way each requires the other or that each alone is unsatisfactory, but cannot perform both simultaneously. These tasks require and preclude each other.

This sense of the quasi-independence of theory and doctrine thus not only motivates the double agenda of the post realist scholar - it simultaneously makes that agenda extremely difficult to fulfill. The able post-realist squares this circle by shuttling across the boundaries between law and other disciplines and between criticism and construction.

To suggest how this might work, let me sketch two broad schemes of interdisciplinary importation typical of post-realist scholarship. On the one hand, we find formal, analytical methods of analysis similar to the objective logic of the empirical sciences - but also familiar from analytic philosophy. On the other, we find intuitive, idealistic or moralistic methods of analysis similar to those used in aesthetics or art. The invocation of "politics" might take either form - as an imperative, even factual science or as a realm of artistic discretion.

Normally, the constructive doctrinal work of the post-realist employs the more objective methodology. In the constructive project of doctrinal elaboration we typically find the logic of empiricism and formalism. Normally, by contrast, the post-realist undertakes his constructive theoretical work with the tools of intuition and aesthetics. 
Of course, this association of methods and realms of work is not fixed in the constructive work of mainstream scholars. One finds also constructive doctrinal work which is inspired by elegance or idealism and scholars whose theoretical work is rigorously analytical. Yet, although the associations of the two methodologies with theory and doctrine might be reversed, these distinctions mark the difference between theory and doctrine in the constructive work.

Post-realist criticism, on the other hand, often achieves its bite by reversing these associations. Doctrinal formulations which had been formally elaborated are criticized for their moral bankruptcy. Theoretical elaborations which were idealistic are criticized as logically or empirically or analytically unsound. A thoroughgoing reform-minded mainstreamer will exploit both of these aspects of constructive scholarship to develop his criticism. Just as constructive scholarship uses analytic methods to develop theory and aesthetic methods to elaborate doctrine, so reformers often reverse their methodology in response.

So long as the fundamental division between analytics and aesthetics is maintained, scholarship can be both constructive and critical. Yet as long as analytics and aesthetics remain distinct, legal scholarship cannot be constructive and critical at the same time or in the same voice. Only a shifting identity can sustain the omnibus project of critique and construction. And a shifting identity only seems sustainable so long as aesthetics and analytics remain compatible - with each other as much as with law. But this does not seem possible for long. Indeed, the post-realist's basic experience of empiricism is its contentless generality, its obliteration of meaning, just as his basic experience of morality is its groundless individuality.

We might summarize the mechanism by which the post-realist elides this dilemma by saying that mainstream scholarship works by displacing into the difference between alternative disciplines (science and morality) a distinction which it seeks to blur within the law itself (doctrine and theory). The movement occurs through the juxtaposition of constructive and critical voices in the post-realist text.

As a result, mainstream scholarship, although inspired by realist insights into the inseparability of law and life or of theory and doctrine and often inspired by literatures from other disciplines which criticize these distinctions, repeat them in their own work. It is a repetition they develop as a relation among interdisciplinary alternatives. They might use history to attack law's idealist claims and logic to demonstrate that law's purported scope is unsustainable and then turn to functional sociology to elaborate law's actual terrain and analytic philosophy to sustain law's normative claims. And so on. No less a figure than Justice Benjamin Cardozo put it this way: "History or custom or social utility or some compelling sense of justice or sometimes perhaps a semi-intuitive apprehension of the pervading spirit of our law must come to the rescue of the anxious judge and tell him where to go". 
The result is an interminable discussion in flight from the closure it seeks. In repeating this distinction, while embracing the very ground from which it might be rendered visible, the mainstream avoids direct inquiry into either their knowledge or their activity, recreating each by reference to the absent other. The play of references which results might seem either incoherent, alienating and generally unpleasant, or inescapable, necessary and desirable. However one feels about it, the most significant accomplishment of mainstream scholarship is precisely this uneasy interminability.

As a result, mainstream work places law and its intellectual other as well as the enterprises of criticism and reconstruction in complicated relationships of interdependence. This embrace - even dependence upon - the intellection and criticism which threatens the law they would defend is their shrewdest achievement and a bold expression of their complex relationship to the realist scholarship which they seem to have displaced by simultaneous affirmation and denial.

\section{The critical legal scholar}

Let me turn now to the CLS movement, like "law and economics", a self-conscious scholarly opposition to mainstream post-realism which emerged slowly during the seventies. In this description of CLS, I am less concerned with the nuance of their arguments, with their historical specificity, with the substantive claims they have advanced in particular areas, or with their methodological claims than I am with their relationship to the mainstream problematic of law and intellection. It is here, more than in any specific insight or advance, that CLS shows both its opposition to the mainstream and its situation within mainstream American legal culture.

The CLS movement seems to have been initiated at least partly by scholars working within the mainstream who wanted to emphasize the various critical strands of post-realist work. CLS scholarship became distinctive when it began to tackle more directly the complacency of eclectic mainstream liberalism in both its constructive and critical phases. To do so, critical legal scholars, like their eclectic target, turned to intellectual traditions developed elsewhere. The work which has resulted pursues a wide variety of critical strategies. Let me begin with some general remarks about the interdisciplinary predilections of CLS and then focus for a moment on two European intellectual traditions which have been particularly influential: critical theory and structuralism.

To an extent critical legal scholars simply assert the authority of alternative disciplines, preferring philosophy to sociology, continental to analytic philosophy and so forth. Partly they recast the assertions of mainstream scholars as doubts, reversing the relationship between theory and practice, law and politics, prescription and description, construction and criticism in mainstream legal scholarship. Partly they take mainstream claims one at a time, severing them from their fluid interrelationship with their negation in mainstream 
work, and extend them seriously until they succeed or collapse. Thus, the CLS scholar might both assert that although law and politics are, as the mainstream maintains, interdependent, politics predominates and that legal doctrine, argument and history should be analyzed autonomously, stripped of any post-realist "policy" or "sociological" explanation. This account might be introduced by a lengthy footnote to various continental philosophers. To the extent CLS work has heightened critical tendencies in mainstream work, CLS scholarship has remained as methodologically eclectic as that of the mainstream. In their own way, they restate, even exaggerate, both the independence and the authority of legal culture. And these critics have been able to claim both to have taken interdisciplinary work more seriously than the mainstream and to have refused eclectic apology in favor of a return to the traditional texts of the law; to have resurrected realism where the mainstream rejected its insights and to have refused realism's idealism or empiricism or skepticism where the mainstream extended the realist's departure from legal doctrine and theory; to have both rejected and inherited the "law and society" literature of the sixties and seventies.

Let me pause for a moment to consider the similarity between CLS and mainstream work on this count. This common eclectic diversity distinguishes both groups somewhat from the work of law and economics, and makes it more difficult to understand the sense in which CLS is understood as a challenge, even an affront, to the mainstream. Indeed, at this level, the law and economics movement seemed a far more promising strategy if radical separation from the mainstream were the goal.

Early law and economics was far more uniform, and far more dismissive of the mainstream method and problematic. Although the problem posed by the mainstream remained central, law and economics, especially at its most exuberant moments, claimed - in a telling repudiation of the mainstream's careful equivocation - to have found an answer. Gone was the hesitation about method, the uneasiness about both abstract models and direct empiricism, the tortured individual judgments about the requirements of legal culture. In its place was a wholesale departure to the discipline of a foreign discipline.

Early CLS work, by contrast, continued the mainstream's eclectic method and seemed to reject only the apparent object of normal legal science - the image of a final resolution to doctrinal quandary. The approach remained uneasy about other disciplines, about theory, about practice and about everything except the internal workings of legal scholarship itself. If we think of the mainstream as the voice of modernism in legal culture, it was law and economics which broke first and most resolutely from its fragmented voice. And yet it was the challenge posed by critical legal studies' similarity which seemed most threatening to mainstream sensibility, as if they remained more attached to an unrealized program of completion or finality than to the mechanics and integrity of their own thought.

In another way, however, these two schools seem simply to have taken different roads away from the mainstream's unease about intellection to conspicuous erudition. For law 
and economics, the road to rebellion seemed a radical completion of the mainstream's program, whatever the methodological consequences. If you want to resolve these agonizing difficulties, to be free of your anxious indecision, they seemed to say, watch this. CLS, on the other hand, sidestepped the program to pursue its rebellion in the lexicon of a radical completion of the mainstream's method. They seemed to proceed through intellectual sophistication, eclectic elision or uneasiness about practice - and out the other side.

For the CLS scholar, intellectual eclecticism is as troubling as it has been for his mainstream counterpart. No more than the mainstream scholar is he able to be confident on foreign terrain except to the extent he replaces mainstream hesitancy about theory with conspicuous erudition. But just as the mainstreamer's critical demand for intellection intruded on his legal autonomy, so the critic's desire to take seriously doctrine's autonomous claims threatens his intellection. Moreover, the CLS scholar remains a legal academic, gripped by the profession's paradoxical relationship to other disciplines. To the extent the CLS scholar recapitulates the mainstream movement between law and life, theory and doctrine, criticism and construction, he also feels each term's attack on the pretense of the other.

The parallel structure of CLS scholarship is expressed by its relationship to certain extralegal philosophic literatures. Let me take two European intellectual traditions which have been particularly influential in CLS work as examples: critical theory and structuralism. Although most recent interdisciplinary foraging has continued rather than questioned the tendency to oscillate between complementary forms of theoretical and doctrinal work, critical legal scholars who have become convinced that the problem is a failure to relinquish the distinction between theory and practice have turned to literatures which take as their starting point a rejection of this disjuncture. Like those in the mainstream who have begun deploying notions gleaned from literature which recognizes these difficulties (most notably the traditions of hermeneutics and literary criticism), this interdisciplinary maneuver has more often repeated than resolved or rejected the difficulties which motivated it.

The first wave of CLS scholars hoping to escape the mutual embrace of mainstream criticism and apology often relied on what they took to be the continental traditions of critical theory and structuralism. The invocation of these particular traditions signaled an ambition to refuse post-realist modesty and eclecticism - at least to the extent it seemed anti-intellectual. That signal was sent partly by the obscurity and novelty of relying upon such remote high cultural texts - by seizing the intellectual high ground. Partly it was sent through the vaguely received sense that these two traditions were "about" getting out of the theory/practice circle. These messages seem much more important than any "application" of these traditions in critical legal scholarship. Indeed, the very offhand quality of their invocation (often reduced to a self-effacing string-cite in a first footnote) mocked the idea of methodological application or interdisciplinary importation even as it 
seized the intellectual high ground. If atypical of scholars importing any particular nonlegal intellectual tradition, this mockery was quite consistent with the mainstream's general uneasiness about association with the complexities of "fancy theory". These two traditions, however, were associated with rather specific methodological projects projects which restated in an odd way the difficulties of post-realist scholarship. Critical theory was understood to proceed from the relationship between attempts by Hegel and Marx to locate the source of the dichotomy between object and subject in history or to locate the identical subject/object of history which would transcend the antinomies of traditional philosophy and the alienation of bourgeois life. As one after another proposed historical subject failed to fulfill this role, critical theory developed a rich literature of explanation, critiquing the social mechanisms which are thought to reproduce alienation. Each critique was supplemented by a relocation of the aspiration for liberation. Brought into law, this theoretical enterprise became associated with a dialectical historical revisionism and a series of increasingly formulaic excuses for continued injustice supplemented by a heroic invocation of practice.

Structuralism, on the other hand, was understood to have begun by suspending the question of historical origin, separating the fluid present moment from the text of its past and future. This suspension of the search for historical transcendence permitted an elaborate series of explorations into the relational nature of meaning. But these analyses were always supplemented by shadow theories of the origin of the social relations or structures which they analyzed. Brought into law by CLS scholars, this foreign method was often stripped of these supplemental assumptions, leading to desiccated analyses of form - supplemented by a heroic invocation of theory.

At least in this crude tendential form, the difference between these two European imports seems to repeat the difference within the mainstream between practice and theory. Critical theory is to practice as structuralism is to theory. As so often in mainstream work we find a difficulty handled by projection onto a difference among imported intellectual traditions - even if that projection demands a reduction in the sophistication of the trends it imports. The overall impression is more important than the particulars - all the bases are covered. Indeed, individual works of critical legal scholarship often surround a dense structural analysis of doctrine with an introduction and conclusion in the style of critical theory - suggesting that "legitimation" or "false consciousness" or whatever provides a link between the limits of form and the impossibility of history.

For all this repetition, however, these traditions seem shrewd choices, for each is more complicated than that. If challenged on the reductions necessary for the project as a whole, the CLS scholar can easily beef up his imported literature. Critical theory seems to worry about nothing so much as its reliance on a historical subject, and structuralism seems preoccupied precisely with avoiding the mechanics of form. 
Moreover, both disciplines sought to dislodge the complacent everyday perception of reality. They shared the conviction that the paradigmatic interpretation which underlies the most prosaic of observations has an anesthetizing and alienating effect upon those who hold it, which can be overcome only through a traumatic reinterpretation of reality which changes the world for the observer. This common dimension fit nicely with the CLS demand for extra-legal assistance in the project of refusing mainstream legal scholarship.

My sense is of an import trade which worked at two levels. First, a rather crude use: of structuralism to complete, pursue or radicalize the mainstream project of doctrinal elaboration and construction, and of critical theory to complete, pursue or radicalize the mainstream project of positioned, perhaps historical, critique. Second, a more sophisticated use: of structuralism to defend the impossibility of formal elaboration and of critical theory to defend the impossibility of contextual ground.

Thus, we find an interesting and crucial reversal of the mainstreamer's sense of the sophistication of law and the crudeness of interdisciplinary borrowings. Suddenly, thinking is sophisticated and law is crude. And the mainstream self-assertion as legal judgment, however effaced, has become the self-assertion of the CLS intellectual - if you like, a move from knowledge to power. This rather contradictory rhetorical deployment proved for a long period an unassailable combination, challenging the mainstream even as it recapitulated, even deepened and honored, the mainstream's interdisciplinary method and eclectic rhetorical style.

But this recapitulation has proved troubling. I have said that in a certain sense, the disciplines of critical theory and structuralism merely restate the theory/practice problem from which the critical legal scholar sought relief. And indeed, for all their equivocation, in the final analysis, it seems that, as imported into legal scholarship, critical theory has stood for the valorization of a posited transcendental subject, just as structuralism, has encouraged the tendency to posit an origin for autonomously investigable doctrinal activity. As a result, neither critical theory nor structuralism has provided a "method" which lawyers can "deploy" against their theoretical and doctrinal malaise. Although useful in establishing a stance against mainstream scholarship, they have not proved able to sustain a long term project of critical analysis.

Instead, much critical legal scholarship has simply oscillated between assertions of doctrinal indeterminacy sustained by a social theory and invocations of social spontaneity sustained by mechanical doctrinal or rhetorical maneuver. It is little wonder, then, that CLS importation of these critical artifacts of high culture should mimic the uneasiness of mainstream eclecticism - that the reference should be in the simultaneously arrogant and effacing first footnote, for example.

Because the CLS scholar replicates the eclectic inconsistency of mainstream work, he too must struggle to ground his fluid maneuver somewhere. Despite his affirmation and 
recapitulation of much of legal culture, the CLS scholar often finds this ground is his relation of opposition to the parallel eclecticism of mainstream work. But in doing so he acknowledges his relationship to that work, permitting the mainstreamer to resolve his dilemma by standing firmly for the defense, despite his own willingness to criticize.

In this, we might think of CLS as having initiated a repetition within legal culture - between the crits and the mainstream - of a difference mainstreamers experienced as a relationship to practice and theory or between disciplines suitable for importation. And it should come as no surprise that many of the debates between mainstream and critical legal scholarship take the form of argument about who, for better or worse, is more theoretical, intellectual, engaged, and so on.

Thus, perhaps somewhat paradoxically, we find the radical extension of the uneasy reliance upon foreign disciplines intensifying the internal flavor of legal scholarship. This turn inward, or loss of faith in the stability of the always uneasy relationship between law and the realms of thought has a couple of important consequences. First, it puts a great deal more pressure on the relationship between legal culture and the world of politics, practice and action - a relationship which I will discuss in more detail in the second part of this essay. At this stage, suffice it to say that this is most definitely not the problematic of law and economics. Having pursued a far more aggressive methodological transformation, they seem untroubled by anxiety about the relationship between theoretical models and doctrinal practice.

Second, and perhaps more importantly, this systematic disciplinary internalization of the relationship between law and thought models what was perhaps critical legal studies' single most important scholarly contribution - and one which would be repeated and extended as CLS developed. The central contemporary reorientation of the relationship between law and politics - the claim that law is a restatement of its imaginary relationship to society - has been developed by bringing the margin (society - politics - economy) into the core of law, rather than by trying to stabilize and relate one to the other. It was this change which marked the difference between the "law and society" movement of the sixties and seventies and CLS. A great deal of CLS work has been preoccupied with this maneuver, documenting within the corpus of legal doctrine or the structures of legal historical change distinctions - between public and private, objective and subjective, etc. which model the anxious and uncertain relationship law imagines itself to have with the rest of social life.

A snapshot of the legal academy after the collapse of the law and society movement, after the proliferation of post-realist apology and critique, and after the institutionalization of CLS, would consequently reveal a complex set of mutual dependencies and recapitulations. Such a snapshot would capture a set of relations marked by shifts in emphasis and by changes in extradisciplinary focus. In it we would see realism recapitulated and rejected by the mainstream, the mainstream recapitulating within itself its own paradoxical 
relationship of defense and criticism to realism, and finally CLS alternatively recapitulating and rejecting both realism and the mainstream. Each of these turns would be marked in part by changing relationships to the world of ideas outside the discipline of law.

\section{CLS - a second look: the post-modern legal scholar}

It is perhaps too early to begin documenting developments within CLS. In a most preliminary way, however, it does seem that something about the tone and style of CLS work has changed over the past decade, particularly as younger scholars, many trained at least partly by CLS teachers, have begun producing scholarship of their own. For our purposes, it is significant that this second wave has marked its difference from earlier CLS work in part by a shift in interdisciplinary allegiance - turning now to extra-legal literatures which themselves responded to the structuralist and neo-Marxist texts relied upon by the first generation of critical legal scholarship.

By 1980, the rotation of academic generations in the legal academy had sped up, each marked by an affiliation with a new set of extra-disciplinary readings and authorities. These generational departures, like the move from the mainstream to CLS, have been motivated both intellectually and institutionally. The institutional demand for scholarly production and innovation remain telling despite what have seemed the dramatic departures from the mainstream executed by law and economics and CLS. It now seems possible to carry out that innovative production within their lexicons.

To an extent, this body of work has simply amplified individual insights rooted in earlier CLS work. Sometimes, for example, the openness of the doctrinal fabric, asserted by CLS as a realist inheritance, has been pursued with renewed vigor and theoretical sophistication and single mindedness, cut loose from its complicated participation in a more stable image of the legal process. This work has also continued and deepened the structural critique of doctrine by fleshing out particular recurring rhetorical forms, such as the relationship between rules and exceptions, in mainstream work.

At the same time, this later work has shifted emphasis somewhat. The search for historical context has been partly displaced by an interest in the processes of textual development. Just as CLS set aside the mainstream concern about stabilizing a source for law's legitimacy or identity, so this later work has seemed at times to set aside the concern to demonstrate the dominance of the margin by the center, the uncertain by the certain, or the informal by the formal in legal culture in order to pursue a more experimental, shifting critical practice. Sometimes this has resulted in a more fluid style, in a move from structural symmetry or historical domination to an exploration of the rips, tears and unpredictabilities in the law or of the personal, experiential and private in legal practice. 
Much of this rather diverse work is marked by invocation of the work of post-modern or post-structuralist French, German or American philosophers, cultural anthropologists and feminists. The works of such as Barthes, Baudrillard, Bourdieu, Deleuze, Derrida, de Man, Foucault, Irigaray, Kristeva, or Lacan seemed to respond quite directly to the relationship between critical theory and structuralism which had troubled critical legal scholars. As a philosophical matter, these works seem to be trying to reintroduce the historical subject bracketed by structuralism without falling into the mechanical determinism or transcendental nostalgia characteristic of late critical theory. Their work shifts among the affirmation, denial and transcendence of the prevailing relations between subject and object which reasserted themselves within critical theory and structuralism. In that they seemed to promise a way out of precisely the dilemma of early critical work.

We might also understand the fascination these new texts held for second wave CLS folks by focusing on their sophistication. I said that CLS work contained both a crude and a sophisticated version of both critical theory and structuralism, and that these two versions worked together to stabilize CLS as an alternative to the mainstream. We might think of the second wave as a no holds barred extension of the sophisticated readings. And these works were suitably current, obscure, available in paperback, and themselves often monarch notes to philosophic texts too dense and daunting for the young legal academic uneasy about traversing foreign terrain.

Separated somewhat from the mainstream project, the young critic could more easily indulge a wholehearted turn to philosophy and the embrace of foreign thought - exactly as law and economics had done. In this sense, much of this newer work seems more clearly to have left any dialog with the mainstream behind, becoming preoccupied with completing the insights of critical and structural commentary on the impossibility of definitive doctrinal or contextual elaboration. What began as extensions of the constructive doctrinal and critical theoretical projects of the mainstream (into structuralism and critical theory) now seemed to have left those projects behind even as the insights (from structuralism and critical theory) which had made the original repetition possible were extended.

This departure to the zone of pure thought was by no means a comfortable one. For one thing, such a strong departure from the mainstream - even if it seemed simply an extension of what CLS had been doing all along and no more dramatic in its move to interdisciplinary terrain than law and economics - was difficult for legal academics to sustain. The air got thin way out there, so far from law into theory. The cruder assertions of earlier CLS scholarship had stabilized more than critical legal studies' relationship with the mainstream - they had also stabilized the CLS scholar as a legal academic.

Moreover, the uneasy fascination of legal academics for fancy theory is in some sense rendered more acute by the very traditions these scholars sought to import. Just as CLS scholars had difficulty accommodating the aspirations of critical theory and structuralism to their continued participation in a scholarly discourse of doctrine and theory, so the post- 
modern has difficulty accommodating the anti-disciplinary aspirations of post-structuralist thought to his continued participation in the culture of the legal academy. Indeed, nothing could be more at odds with the post-structuralist enterprise than an invocation of the certifiably erudite European. This wave of European theoretical work is about refusing precisely the model of theoretical application, philosophic importation, indeed of definitive scholarly analysis which seems signaled by the suggestion that "one really must read Foucault to say anything meaningful about the Uniform Commercial Code".

In the event, however, perhaps the post-modern has not ventured so far - perhaps, far from departing law's ambit, he honors law with his philosophy. For all the new citations, much post-modern legal scholarship echoes a great deal that was familiar to the mainstream and to earlier CLS types. For example, like the mainstream, the post-modern moves subtly between legal text and legal culture, recapitulating the move to theory as supplement for an argument of historical context or doctrinal elaboration. At this preliminary level, moreover, it seems that the distinctions within post-modern legal scholarship between say, Foucault and Derrida or feminists and Frenchmen recapitulate the relationship between critical theory and structuralism which kept CLS in legal discourse with the mainstream - itself divided between projects of criticism and reconstruction which relied upon traditions of history and logic.

Or take the relationship between openness and closure in legal culture - the post-modern seems as fascinated as the CLS scholar by the difficulties posed for the mainstream project of an independent and forceful law by the fluidity of doctrine. In earlier work we found a strongly asserted indeterminacy of both historical causation and doctrinal elaboration coupled with, surrounded by, imbedded in, some crude theory of historical agency. So here, we find the indeterminacy of legal doctrine and the impossibility of definitive historical accounts passionately defended, and often imbedded in some theory of narrative, of perspective or of the priority to be accorded some particular "telling".

Yet here we also begin to see what is distinctive about post-modern work, for the preoccupation is strangely reversed. Where CLS had focused on indeterminacy, the postmodern often seems to focus on the mechanisms of closure, imbedding a complicated account of doctrinal privilege and historical happenstance in a rather crude assertion of indeterminacy.

Or take the CLS fascination with internalization, with identity, with the inside of legal scholarship. If anything, the turn inward has been accelerated by the later generation. For CLS this preoccupation usually took the form of a critique of the legal process, and an assertion of the autonomy of the legal academy. We saw this in the importance which the relationship between the mainstream and CLS came to have. For the post-modern generation this has often taken the form of a critique of the legal academy - of the interpretative process - coupled with a more aggressive assertion of self. Thus, we find work about CLS - and about the relationship between CLS and the writer rather than 
between CLS and the mainstream - and about the experiences of the author, documenting the professional, the personal, and the private. In this we can see the agency of scholarship in motion - from the judgment of the mainstream, submerged in process, through the importance of the movement, submerged in argument, to the strong valorization of the self in post-modern work. And this final move is an odd one, for the interdisciplinary literatures relied upon by the post-modern concern little so centrally as the disestablishment of the autonomous self.

Before exploring the difficulties posed for the post-modern legal scholar, by this preoccupation with the self, we should begin to take note of the mechanisms which mark distinctions among scholarly strands. As we saw, CLS marked its difference from the mainstream in two ways. First, by extending and separating the projects of construction and criticism by moving to critical theory and structuralism. Second, by rearranging the relationship between method and program, theory and practice, insistence and humility. The move from early CLS to more post-modern scholarship was marked similarly.

Like CLS, the post-moderns began with an extension of the project of their predecessor, marked by a change in interdisciplinary affiliation. The rearrangement of the CLS project was most clearly marked by a series of reversals: from openness in the shadow of closure to closure in the shadow of indeterminacy, from legal scholarship in the shadow of theory to theory in the shadow of legal scholarship, from analytic sophistication in the shadow of crude theoretical reduction, to theoretical sophistication in the shadow of crude selfassertion, and so on. If the theoretical voice of CLS had been coy, the post-modern seems bold. Where the CLS preoccupation with the distinctiveness of his movement, and, as we will see, of his politics, had been bold, the post-modern is more likely to demur. Where the CLS author reconfirmed the humility of the mainstream, the post-modern tended to flaunt his fascination with Nietzsche, with an overfilling of boundaries, an exuberance, and the assertion of play. In short, if CLS had explored the reversals within mainstream legal doctrine and culture, between public and private, or objective and subjective or among rules and standards, the post-modern work models this reversibility in its relationship to CLS and the mainstream.

However marked by shifts in interdisciplinary taste (down with Marx, up with Nietzsche) these reversals are most important as shifts in emphasis and tone - shifts, in other words, of voice, rather than alternations between program and method as the mark of scholarly distinctiveness. And in general we find in post-modern work a move to rhetoric, to the study of argument, which simply sets aside the content and objective of the scholarship under study. At first glance, this move to rhetoric seems comfortable. It seems to return to the legal process - not the process of institutions or doctrines, but of conversation. And yet, this move confirms the scholar's involvement with the self, for what marks a man's character so plainly as his argument? 
This move to voice and this strange post-modern assertion of self are troubling. For one thing, the move to an interactive process and the move to self seem somewhat at odds with one another - and it is unclear how the notion of rhetoric might unite them except as an assertion that they are joined. Indeed, the problem should remind us of the difficulty the mainstream encountered squaring the independence of law with its critical bite. To sustain this double assertion, the post-modern is likely to resort to a certain crudeness of his own - using the move to rhetoric to flatten rather than enrich the complexity of both self and context. The famous incantation "there is nothing outside the text" comes to mean "there are only texts" rather than "all the outside is always already in".

American legal scholars of the post-modern persuasion, no less than other American interdisciplinary poseurs are thus subject to indictment for desecrating the insights of thought in the service of law. Purists might find their "use" of Derrida partial, reductionist, mistaken, banal. Post-modern legal work appears this way to those who behold it from other disciplines because the law is all of these things, because the enterprise of eclectic cross-disciplinary ingestion is all of those things, because legal scholars normally don't have PhDs.

As it was for CLS, however, this crudeness is an integral part of the post-modern's ability to sustain his argument and integrity. It is by oscillating between sophistication and crudeness - between insight and its denial - that the post-modern approaches the old problem of doctrine and theory. The impossibility and necessity of both can only be simultaneously comprehended by a single voice if that voice is both assertive and disembodied. Like CLS, the post-modern combines a critique with a restatement. The stability of post-modern scholarship is provided by the continuity of the voice - the recognizability of irony perhaps - which can both return to retrace the statements of the mainstream in an arch reversal of CLS criticism while extending the CLS theoretical critique.

This only works so long as overt discussions of theory are avoided - or so long as the sophisticated theoretical proof that the post-modern has accepted and gone beyond the criticisms demonstrated by critical legal studies' interdisciplinary roamings can be separated from the post-modern's rather crude return to mainstream elaborative projects. We might think of the post-modern trying this social experiment: nodding earnestly with the mainstream while winking at CLS, and then debating furiously with CLS while winking knowingly at the mainstream.

It is perhaps the anxiety generated by this exercise which has led to the rather more overt efforts at self-expression in post-modern scholarship - and to efforts to ground the wink and the nod in some social margin. Much of the later CLS work has been preoccupied with issues of gender, race and personal identity or with the work of CLS and the process of working. Thus, the flight to self-assertion has been coupled by an equally striking flight to the voice of social marginality. We find then, at the core of the post-modern's turn inward, 
an echo of the mainstream's anxiety about the simultaneous autonomy and connectedness of law itself, restated here as an identity problem.

The post-modern extends the CLS turn from discussion of the relationship between law and social life to an internal focus on the law. He also extends critical legal studies' internalization of the social context within law - its focus on law as a restatement of its relation to some social periphery - to a new exotic periphery, to the female, the black, and so on. This move focuses on the identity of law, of the legal scholar - indeed of CLS - as a recapitulation of its relationship to this margin - seeing in the CLS practice of assertive engagement a method which is white and male.

This move to reawaken or capture - or, less kindly, to exploit - the exotic margins of establishment culture has a theoretical and contextual face. We find in later CLS work far more invocations of the theory of feminism and of racism, even a suggestion that the legal scholar's interdisciplinary roamings be pursued on an affirmative action basis. The more important face, however, has been political, institutional and pragmatic. The move from early to late CLS has been conducted far more overtly as a transformation in the political commitments and deployments of the movement than as a change in interdisciplinary focus. To explore that transformation, we will need to think more broadly about the relationship between legal scholars and the world of politics.

\section{Legal Scholars and the World of Politics}

Legal scholars have an uneasy relationship to political life. To an extent this expresses contemporary legal culture's uneasiness about the relationship between law and politics. At least since the New Deal, legal culture has presented its relationship to political culture in a variety of ambiguous ways. Law purports to be both above, removed, or neutral with respect to political life and the procedural rules, the instrumental expression, the forum and historical embodiment of political culture. Although certainly independent and able to bring its own unique attributes to the process of social management, after realism, law has come to seem fully enmeshed in the political process.

To an extent, the legal scholar's uneasiness about political life expresses the legal academic profession's struggle to sustain its distinctiveness in the post-realist period. The difficult double relationship between law and politics characteristic of legal culture generally is recapitulated in the legal academy's self image - most particularly in the relationship between legal academics and their classmates in government and legal practice. As academics, we want to be less political than they, but as lawyers, we feel we should be more political than our colleagues in the human sciences.

To get around this difficulty, legal academics often style themselves as judges - above, beyond, neutral with respect to the interested party or practitioner, and after or innocent 
of the messiness of legislative or sovereign choice. As scholars, associating ourselves now with the world of ideas, we may even style ourselves as judges of the judiciary, making assessments in teaching and writing about cases which were "correctly" or "incorrectly" decided. But we also pose as the facilitator, partner and servant of both the practicing lawyer and judge - "restating" their wisdom and training their staff. In our teaching we speak the law in both of its voices - as a disembodied apolitical culture which simultaneously transcends temporary political accommodations and seems trivial in its technical detail and as a set of procedures and instruments within which we situate and express ourselves as political citizens.

This double relationship to politics is reassuring to those of us who are in fact uneasy about the instability of public political commitment. The legal scholar, like the law, can seem both engaged and secure. Politics, with all its passion and intrigue, can be enjoyed as a pastime or private avocation. When it comes to politics, the legal academic typically marks within himself a division between public and private, an internal division between institutional or professional neutrality and private commitment or consumption. But this division has another, less conscious, dimension. For the legal academic remains professionally neutral precisely to preserve his role in public politics, and consumes his politics privately precisely because he regards the private as the zone of frivolity.

In public, perhaps in the classroom, the legal academic typically presents the law as both too delicate to withstand the ravages of direct political struggle - in need of his protection and fealty - and as the honorable and direct expression of well considered political accommodation. Politics in the classroom seems both destabilizing, a breach of faith, threatening our special expertise, collapsing our discipline into a pale technical colony of political science and necessary, ennobling our analysis of the Constitution, the arguments of common law judgments or the legislative background of some New Deal statute.

This public faith is sustained by a private cynicism. The legal academic is not naive - he knows this image of law's relationship to politics cannot be correct. In between the lines, between his lectures, in the anecdotes, he communicates a cruder vision - of politics everywhere, of himself as a public personage, responsible. And he is responsible both to assert the judgments of faith and to admit the realism of power. Above all, the legal academic is balanced in his assessment of himself, his politics and his law.

\section{The mainstream reformer}

The mainstream legal scholar manages these uneasy relations gracefully, in a complicated series of practices. A moonman might be struck first by the fact that nobody in mainstream legal academia talks very much about politics. Professionally, the mainstream legal scholar typically shares legal culture's comfortable distance from partisan political commitment and he typically comports himself in both teaching and scholarship so as to avoid political 
advocacy. But this impression will easily give way - like those perceptual tests which resemble either a rabbit or a fence - to the impression that mainstream legal scholars talk of nothing but politics.

A common fantasy about "politics" sustains this double image. Mainstream legal scholars generally equate politics with the state. It is the state which provides the arena for political action and makes political choices. It is the state which recognizes people as citizens and employs people as politicians. In this arena, in the struggle of interests and commitments, the political remains resolutely a matter of the conscious, of the public, the visible, the overt. For all the mainstreamer might consume his politics in private, he does so as a matter of conscious decision. For the state, there is nothing beneath the surface, just as the mainstreamer knows no unconscious.

The mainstream legal scholar has two attitudes towards this public space. First, he is concerned to retain his distance and independence from the state to retain his status as an intellectual. This independence underwrites the value of his wisdom and the gives him confidence in his class position. Second, he wants to deploy the state, guide it, instruct it, manage it, work for it. He wants his opinions to be transformed into state policy, and for this they must be redolent with political savvy.

Generally, the mainstream legal scholar manages the tension between these two sides of his fantasy about politics by reference to his professional role. Exactly as he might feel a lawyer must argue while a professor must judge, so he has developed a professional image of law professor's politics which squares his desire to preserve his independence with his ambition to serve. The complicated relationships between private advocacy and public neutrality, between public faith and private cynicism, like the relations between constructive doctrinal elaboration and engaged critique, permit the mainstream legal academic to sustain a relationship to political life by mediating it through legal culture and the legal practitioner.

Thus, for example, the mainstream legal academic usually seems to experience his commitment to law itself - to its preservation and reform - as a political expression. He teaches the policy and justificatory argument of legal culture as if it expressed a political commitment and involvement for the legal professional. He often associates himself with the reform work of lawyers. The difference between preservation and deployment is thus displaced from the mainstreamer's personal ambition to the law.

This practice renders the mainstream scholar's politics representational. Although he acknowledges, often emphatically, that law brushes up against politics more directly than he would himself, particularly in the classroom, he serves that law best by his distanced "academic" stance towards it. His own professional political work is usually done in service of the law and the profession - codifying, compiling, systematizing, recommending, proposing, elaborating, and perhaps even advocating legal doctrine. When he asserts 
himself in class, it is in the mode of judgment - about a sovereignty past - rather than assertion about a sovereignty to come.

He must restrain himself in his speech, confine himself to speech, not simply to preserve the foundation for his opinion, but to serve the state - by respecting its commands and entering its service, as citizen advocate or state official. All this edifice of restraint and expression, of preservation and sovereign deployment is ultimately - and no phrase figures larger in the political lexicon of the mainstream - "in the public interest". In short, the mainstream legal academic stands for the political activity of and for others.

The mainstream legal scholar, of course, is neither naive nor earnest about this relationship to political life. He has problematized enough cases and traced enough failed legislative intentions to be cynical about the politics of practice and policy. He may have already come to serve the state or practiced as a lawyer "in the public interest". Indeed it is the distance and doubt, even cynicism, about these activities which generates his position as an academic in the first place. He may be as proud of his savvy as of his judgment.

But this distance also suggests a discomfort, an uneasiness about academic work in the service of a profession. The legal academic's willingness to speak in his own voice about political matters seems diminished - just as he came to seem unwilling to speak in his own voice about the world of ideas. Despite its assertion that politics is the stuff of his profession's practice, the modern legal voice has submerged its political commitment, tying itself to a profession in which he has only the most tenuous faith.

Let me formulate an example. A mainstream teacher might say, when discussing the policy options opened up by some doctrinal discussion, "we could do this, or that, or some other thing - it all depends upon what you want". The voice formulating the legislative alternatives in this way moves from the first to the second person plural in a time and place somewhere between always or whenever and soon, after graduation. Initially - in the opening "we" phrase - such a statement constitutes a class identity somewhere between social engineer and general will and seems located in the present. The second phrase, the implementation, seems addressed to a student body constituted as practitioners, those who will actually live out the practice of social engineering in the public interest while the teacher remains behind in the academy. It is by combining moments such as these - rhetorical moments - that the mainstream legal scholar is able to retain both his independence and his ambition.

\section{The critical legal scholar}

In the eyes of the mainstream academy and the press, it has been the politics of CLS which have most clearly marked the movement as an opposition. In many ways this seems odd, for the politics of CLS is structured much like that of the mainstream, continuing the 
mainstream's troubled and anxious relations with political culture. A first statement of CLS politics might have three credos: to the left of the mainstream legal scholar, with the progressive practitioner, for the socially marginal. There is little here to differentiate the CLS legal scholar.

The first point might simply be a matter of personal, private commitment, and it troubles the mainstream to feel it is bothered by the politics of its colleagues. Moreover, CLS scholars presumably oppose mainstream legal academic culture partly as representative or handmaiden or "reproducer" of legal culture's bad politics. In this sense, as legal scholars, their politics is similarly displaced through academic activity onto legal culture and the legal profession. To the extent CLS scholars imagine themselves to be working in alliance with progressive practitioners - with whom they have as uneasy a relationship as that between mainstream legal culture and the profession - they seem to reaffirm the mainstream's commitment to politics by others. When they imagine that a legal scholarship of doctrinal elaboration and criticism executes political commitment, they seem to reaffirm the mainstream's image of a removed scholarly identity. When the CLS critic situates himself with the mainstream academic, as a scholar working on behalf of practice, valorizing the practice of the left bar, he reaffirms the lawyer's representational role - in the public interest.

Taken a bit more slowly, the politics of CLS scholars might seem an extension, or perhaps "radicalization" of the political culture of the mainstream legal academic. Understood this way, much of what CLS does might well sound like a challenge to the mainstream. Sometimes, for example, the critical legal scholar would take the mainstreamer up on his claim to independence, asking for more unencumbered political speech by legal scholars. If you believe it, why not say so? The move to a more overt tone by itself seems important, for it seems to bring political commitment and doubt into the legal academy. Yet it was precisely the encumbered nature of political speech which made politics seem possible to the mainstreamer. Open, unabashed reference to politics in law teaching makes people students, colleagues, and, most importantly, I think, the critical legal teacher himself uneasy.

For the CLS scholar, the overt display of politics in the classroom or in writing threatens his participation in the culture of legal academia - undercutting his independence, oppositional bite and believability as resolutely as it would that of the mainstream. Moreover, such overt political commitment often seems to clash with his intellectual insistence on the openness of legal culture - on the impossibility of hooking given doctrines to specific politics and history.

Sometimes, by contrast, the critical legal scholar might take the mainstreamer up on his claim to eschew political speech, resolutely opposing any discussion of "policy" which might obscure his project of doctrinal elaboration and critique. If the law's so autonomous, lets see if it can sustain this. This return to an unapologetic scrutiny of doctrine seems 
important, for it avoids the easy patois of justification. But a strong denial of politics makes legal scholars as uneasy as an overt political commitment. Sometimes it is simply not noticed - it would be just like the left to pretend to discuss only doctrine. Usually it simply increases the pressure for other, severable, but correspondingly overt indications of political commitment.

And indeed, the critical legal scholar sometimes invokes direct political activity - either work as a practitioner (perhaps in a clinical setting), or in the reform of legal education itself. When he does so, he meets the mainstream scholar who has always already been out there in the clinic and who spends an inordinate amount of time with reform of legal education. Nevertheless, the CLS tone again seems different, more assertive, more insistent. Sometimes it must sound to the mainstream scholar like praying on street corners. Yet the tonal change also marks a challenge, extending the mainstream's ambition for sovereign deployment, taking the mainstream scholar up on his commitment to political action.

This challenge is most acute when the CLS scholar brings it home to the legal profession and academy - emphasizing and extending the public interest into the academy and profession. And the CLS scholar - as part of his general turn inward - is often associated with a more aggressive style of faculty politics. Sometimes this means deployment within the faculty institution on behalf of excluded groups - students, minorities, women, etc., bringing the representational political culture of the mainstream into the university. Although these efforts remain representational, they suggest an end to the independence of the institution - as of its unencumbered judgment - as threatening as the move to a more political speech, if for no other reason than that they promise to bring the client home to dinner through affirmative action hiring, etc.

For the CLS scholar, a strident institutional politics is also troubling. No less than the mainstreamer, he might feel these are efforts which cannot be sustained over the long haul, for each success threatens to dilute his authority as an independent academic, slowly strangling the goose that lays the golden egg. With however much macho gusto he might claim otherwise, he too fears he might have to go into practice or seek refuge in philosophy.

Yet if he fears his success, he also suspects that reform of the legal profession cannot possibly fulfill his political ambition. No less than the mainstream is he enthralled with the possibility of a more sweeping sovereign authority. Hiring another woman at your school is not the same as reforming national employment discrimination law. Local efforts seem self-serving, hyped, a distraction from the more important political work of becoming the sovereign's opinion. Strengthening, extending, even radicalizing these mainstream political activities and commitments seemed challenging because doing so in each case heightened the tension between the legal scholars' desires for independence and engagement - for the mainstream and for CLS. At the same time, moreover, advocating both more assertive 
political speech and more engaged institutional politics began to demonstrate the tradeoffs and tensions among the various approaches to politics taken by mainstream legal scholars. More politicized opinions - speaking out as a law professor - and more engaged political action only go together for individuals whose personal cache is stronger than their institutional or class status as intellectuals be they mainstream reformers or campus radicals. For the rest of us, the one cancels the other. Extending the commitments of mainstream politics upset their careful balance.

For CLS, the most important manifestation of this difficulty came as a conflict between their intellectual critique of political program and their proclamation to be on the left. Intellectually, their emphasis on the openness of legal culture seemed a critique of political programmatic work - particular when couched in terms of "rights". How might this opinion be squared with their valorization of political work - particularly work defending "civil rights?" After all, if one accepted their intellectual critique, might not progressive politics be pursued equally well by pushing law to the limit ("completing" the project of liberalism, finally enforcing rights, etc.) as by pushing society to the limit ("deconstructing" and historicizing liberalism, disaggregating rights, completing the project of the market)? Critical legal studies marked its difference from the mainstream when it began developing responses to this dilemma. There have been a lot of false starts - mimicking the resolutions worked out by the mainstream legal scholar for the same difficulty.

Sometimes, the critical legal scholar's critique of program simply means suspending the project of the mainstream - perhaps by refusing to end a law review article with a policy proposal, or by sticking to broad hortatory language about the good society. This tactic is familiar from the mainstream - separating the critique from the elaborative political engagement. Sometimes the CLS critique of program was broader, suggesting the impossibility of coherent programmatic thought. However strong this seemed as an intellectual challenge, it always seemed possible simply to assert that it was not true to anyone's experience - including the experience of the critical legal scholar. Challenged by the voice of political savvy, the CLS scholar could only acknowledge his own political activity, thereby heightening his self-assertion. This position seemed to heighten the distance between the opinion and activity of legal scholars - precisely the gap CLS set out to bridge.

Sometimes the CLS assertion to be "on the left" was simply an assertion - or a reference to private political acts, or activity in the profession. Such assertions are familiar in legal academy - I may seem neutral or disengaged, or whatever, but I'm not, just ask my wife, and by the way, what have you done for the revolution lately. Sometimes, by contrast, the CLS scholar suggests that the intellectual effort of total criticism, or refusal of program, is a left program. But this approach merely echoes the difficulties encountered when denying a political agenda. 
Sometimes, CLS critics assert that despite or alongside or before or underneath their intellectual assertion of the indeterminacy of legal culture, they stand for some collection of programs and positions. After working their way through a critical exercise, CLS scholars often find themselves enumerating a political creed of sorts. For some reason this tendency seems at least partly to be demanded by the very audience which is disturbed by its audacity. Although, the CLS response may be more overt than the mainstream tendency to demur, to shrug, to refer out to the audience or onward to practice, it remains a supplement to their scholarly activity, a product of either right theory or private commitment.

The CLS scholar faces the same desire to square these potentially conflicting positions with one another as does the mainstream scholar. Let me focus on two common responses. First, the CLS legal academic might relate these various positions as "tactics" and "strategy" or "long" and "short" term projects. In the short term, private engaged political commitments to particular programs may be good tactics, but over the long haul, the best strategy is a radical intellectual distance and skepticism about rights, programs, and so forth. Mediations like this repeat the distinction between law and politics within law, as the contrast between an activity tied to thought (strategy) and an activity governed by the vicissitudes of action (tactics). The difference is sustainable, as Clausewitz suggested, only by an exercise of judgment, by self-assertion, by genius - the independent judgment of the representationally disengaged legal academic.

Second, the CLS scholar might stabilize the various strands of his politics by relating them to some other, against whom they are deployed. This approach usually takes the mainstream as its target, but it may also be something as diffuse as "liberalism". In this effort, the CLS scholar recapitulates in his relation to politics an important dimension of his intellectual work. Much of the critical tone of CLS work has been sustained by emphasis on the indeterminate in legal doctrine. Each discovery of indeterminacy (in the doctrines, the cases, the institutions, the results, etc.) works against some unspoken determinacy location (in the long run, the specific outcome). This set of imputed political commitments works like the imputed determinacies of critical scholarship to sustain an overall critical tone.

The CLS critic's destabilization of claims about the political purport of legal culture works against the background of some stable set of political images which are seen to be mediated through the activity of legal scholarship. Indeed there may often be a sustaining relationship between these two maneuvers in the realms of intellection and politics - and it is this relationship which seems to lead the mainstream audience to demand of the CLS scholar precisely the overt political agenda he is loath to hear. One finds the purportedly indeterminate intellectual claim sustaining its purport (and hiding its reliance upon images of determinacy) by reference to a determinate political creed. Similarly, the indeterminate purport of the CLS political critique is sustained (hiding its reliance upon stable client images) by reference to a set of determinate doctrines and legal institutions. 
Beyond these various techniques for stabilizing the CLS movement as a political alternative to mainstream legal scholarship - by grounding it in self-assertion, in a connection to a projected mainstream or client, or in a relationship between intellectual and political work - the CLS scholar has, from time to time, articulated an alternative to the mainstream image of state focused politics. Sometimes, this articulation invokes popular images from the sixties - the state displaced by local constellations, adversarial politics by mediation, alienated citizenship by direct political engagement, representational efforts for the client by pedagogic encouragements to self help, disempowerment by empowerment, the surface style of interest group pluralism by the psychobabble of encounter group analysis. Of course, such an approach retains the image of the intellectual as custodian of correct theory for a political culture.

At its most compelling, however, this alternative vision is somewhat more sanguine about the value of an independent intellectual political caste. In this vision, breaking the sovereign's monopoly on politics, spreading political struggle throughout the institutions and personal relations of civil society, removes the audience for persuasive intellectual opinion - and ends the fantasy that by maintaining one's legitimacy, a legal scholar might some day serve the state, as either an official or a persuasive advocate of the public interest. This vision sidesteps the conflict between preserving the independence of the intellectual and securing his political engagement.

The result has been an intensification of the turn inward, toward the institutions and ideas of the legal intellectual as a terrain for political engagement. The effort is no longer to mobilize legal scholars for something or towards somewhere or on behalf of somebody, but simply to mobilize the legal scholars themselves, treating the institutions of legal education as a site of political engagement on its own. It is almost impossible for the legal scholar to retain this approach. The demand that he explain the importance of this selfindulgence, that he evaluate the long term chances of building a national mass movement if you start with law professors, that he compare his efforts with more traditional political activities in terms of their impact on the social margins is overwhelming.

Usually, the critical legal scholar succumbs to this pressure. At least, he finds himself recommending that others follow his example, organizing their own back yards. More often, he enriches his political practice with vocabulary and preoccupations of encounter group psychology, an insistent self-assertion, and an insistence on the politics of personal, family and institutional possibility.

These assertions are made more plausible by the cultural familiarity of the women's movement and the various self-help groups of the seventies. But these familiarities raise certain problems. Seventies culture now has an extremely bad reputation among serious legal academics. It seems frivolous, self-absorbed, narcissistic, and ultimately unable to do anything "in the public interest". The women's movement, by contrast, to the extent its politics can be pursued by mostly male legal academics, seems at best a representational 
activity - whose benefits could be measured in terms of the concrete improvement in the situation of women in the United States. The CLS scholar thus sustains his political vision by oscillating between extreme versions of self-involvement and self-abnegation - echoing precisely the mainstream's oscillation between preserving the independence of the intellectual class and deploying it in the arena of national politics.

This dilemma is often handled by a certain vague fickleness. As a practical matter, the work product of the CLS scholar has cycled through a number of potential clients, supporting the positions and activities of the political "left" generally or various dispossessed groups. Such invocations often appear in relatively undifferentiated string cite form in critical articles: minorities, women, jews, palestinians, homosexuals, people of color, the third world, and so on. Alternatively, one finds a more general invocation of authentic human relations, of the private, passionate, intuitive world of phenomenologically comprehended face to face human interaction.

These approaches bring certain difficulties in their wake. In the first place, if one were to add senior citizens, shareholders, entrepreneurs, unborn children, neo-Nazis and the middle class to the list, one would have listed those on whose behalf the mainstream also purports to work. And it is not surprising that criticism should reawaken those commitments. But the CLS scholar's relationship to a list like this is a much more troubled one.

After all, much of the intellectual work of CLS criticizes lists - such as lists of rights - which distance legal culture from the objects of its concern by relying upon status categories which themselves reflect the thousands of ways law bisects society. When the mainstreamer invokes these groups, he can remain comfortable about his indirect relationship to them - he pays fealty through belief in the extension of the legal system itself. The CLS scholar, by contrast, must imagine the relationship more directly - must seem to be able to connect his or her work as a legal scholar to these clients without the intervention of the system against which the scholar has defined him or herself.

These difficulties have animated the political development of CLS over the past decade or so. The most significant development has been a change in the way clients are invoked away from the combination of vague generality and intense specificity to a mystical invocation of some single other. In this mode, a single group is singled out and given a special status in CLS. Women are a recent example - we are all feminists. But the invocation, however reverential, is troubling.

On the one hand, the claim may be that women are a group with whom the CLS movement may have rather direct, unmediated political engagement. At the same time, and more mystically, the group is identified as an unspeakable voice, absolutely other to legal culture, the political redeemer of legal work which no longer feels comfortable expressing its commitment directly to a legal client. This absent - and assertively present - subject 
gives the critical work meaning, grounds the work as origin and destination and, more importantly, expresses the "worthiness" of the client as successor. CLS is no longer an oscillation between self-assertion and indeterminacy. When women find their voice, they will displace the ironic tone and resolve the critic's undecidability. The critic can stand the agony of his polyphonous relationship to the mainstream because when god speaks she will be a third world woman.

\section{The second look: CLS and post-modernity}

By and large, CLS has developed by fine-tuning these various political maneuvers. All have been continued by those critics who rely upon contemporary European "post-structuralist" philosophy for their intellectual innovation. To an extent, the political commitments of CLS seem increasingly fragmented, dispersed, private - disconnected from the progressive bar and refocused on legal education and, on the politics of CLS itself. This shows itself partly in treating methodological or genre innovations in legal scholarship - the move to first person narrative and other challenges to the conventions of legal scholarship - as political engagements. To an extent, CLS simply seems increasingly depoliticized, less strident, more bemused or ironic than insistent in its criticism. Indeed, the latest wave of CLS scholarship has been criticized for being apolitical.

Beyond these changes in tone and emphasis, CLS has continued to develop an image of the state, of political culture, and of the self at odds with that of the mainstream in legal scholarship. The image of the state as a "center of power" or a "sovereignty" which actually exists, is factual and is the site of either law or politics or both, which is developed independent of the narrative of law's history, alongside it, before or ancillary to law's image of sovereignty has been increasingly criticized. In this, these critical scholars seem to seek an image of the state as an imaginary relationship between law and politics, as a site for their rhetorical awareness of one another. This image - of a more rhetorical, interactive, dispersed sense of power and thought - has suggested an alternative image of political engagement which does not separate into speaking and doing.

A fair amount of recent critical scholarship describes a politics of rhetoric, of dialog, or language with its own sociological and logical coherence. The ambition is to understand the relations among institutions, individuals, or doctrines similarly. The difficulty, of course, is that such a rhetorical process sounds remarkably like the image of a "legal process" which the mainstream legal scholars of the fifties thought might resolve the difficult political choice between intellectual assertion and engagement. And indeed, much of the most recent work sounds remarkably like earlier mainstream work, the differences matters of tone as much as substance.

Like earlier CLS work, this problem is stabilized somewhat by a combination of selfassertion and reference to a client - but with a difference. Central to the work of legal 
scholars influenced by post-modernity is an elaborate critique of the autonomous self. The result is a great deal of talk about decentering or displacing the voice of the critic and acknowledging the impossibility of the text. Just as central is a critique of representation. As insistent as the invocation of "women", is argument about the impossibility of an essential "woman". This has resulted in an odd rotation among potential clients/selves, as one after another group of new CLS academics have seized control of the conference only to relinquish it immediately - resulting in a vision which might almost seem pluralistic if it were not so insistently one thing or another at each moment.

But the post-modern legal scholar remains in the legal academy, uneasy about the political ambiguity of post-modern work. To the more traditional CLS scholar he may seem less interested in either self-assertion or clientele. But unlike the mainstream, he does not defend the legal academy against the change in tone and emphasis promoted by critical legal scholarship. He seems threatened with mistaken identity from both sides, seeming to acknowledge the politics of scholarship and yet to remain apolitically disparate.

Beyond the rotation among mystical client voices, the post-modern critical legal scholar has sustained his own uneasy position primarily by shifting attention from his relationship to politics onto his relationship to ideas, often by reference to an absent philosophical mentor - much as the CLS scholar worked by reference to an absent client. Names like Foucault or Derrida operate in post modern texts more overtly than they did in critical legal scholarship. No longer confined to a footnote, they float around in the text as people who have discovered one or another truth against which to consider both political and legal culture. In this, the post-modern seems to sustain his position by reversing the relationship of political and intellectual uneasiness. If the CLS scholar reversed the mainstream relationship to both neutrality and doubt within the realms of politics and intellection in order to create a difference from the mainstreamer while remaining in the discourse of the legal academy, the post-modernist seems to reverse the relationship between the political and intellectual tone common to both CLS and its mainstream antagonists. This keeps the post-modern within the project of post-realist legal academia despite the self-consciousness of his imitation of the mainstream and the dispersion of his affinity for the politics or intellectual insights of CLS.

At best, however, this move from politics to intellection simply returns us to law's uneasy relationship to the world of ideas. The best post-modern legal scholarship responds to this difficulty by executing both maneuvers. When the relationship to politics can no longer be sustained, the text switches to the invocation of ideas. When the double relationship to philosophy can no longer be sustained, the text switches to a projection of some political program or clientele. Both moves repeat maneuvers familiar to both the mainstream and CLS. In short, the move which was to save post-modern criticism from manneristic imitation may also be read to have simply continued it. 


\section{Legal Scholarship in Rotation}

In my experience, contemporary American critical legal scholarship is often misunderstood because it is approached as either the theory of left intellectuals or the practice of academic politicians. What is their theory and what do they think should be done? Like American legal scholarship more generally, however, recent critical work is neither a political program of intellectuals nor the theory of lawyers. Rather, we find a distinct group of legal academics struggling with the relationships between their work and the realms of thought and political practice. They are anxious about both politics and thought. And they have no theory or practice or client or party which can resolve their anxiety. As their work has developed, they have simply altered their accommodation to their situation as legal academics.

In this essay, I have tried to relate the work of critical legal studies to the mainstream of legal scholarship, situating it within the legal academy. In fact, of course, legal scholars focus a great deal of energy on the boundaries of their collective project, wondering whether their own or another's project is inside or outside the realm of legal scholarship. Each strand of scholarship considered here occasionally criticizes the others for being either too politically engaged or too intellectually ambitious. The post-modern and critical legal scholar will sometimes claim that the mainstream's interdisciplinary roamings have taken it too far from the core study of legal doctrine or history, or that the mainstream's centrist politics distract it from an understanding of the varied tendencies within legal culture. The mainstream sometimes seems to feel that the critical legal scholar has strayed too far afield politically to remain comfortably within legal academia or that the postmodern seems too enmeshed in philosophical debate and literary criticism to be thought of as a legal academic.

More interesting than these claims to be on the inside, however, is the equally striking tendency of each strand to assert its outsider status. The post-modern is constantly talking about "displacing" the project of legal scholarship as practiced by critical legal and mainstream scholars alike. The critical legal scholar similarly poses as an antidote to the complacency of an insider mainstream run dry. Most remarkably, however, this outsider stance is most familiar in the work of the mainstream. Since the realists, the mainstream has positioned itself against what it has thought of as the autonomous claims of classic legal culture - against both formalism and naturalism. Moreover, the strongest critique leveled by the mainstream against the other two strands is that they are too preoccupied with the law as doctrinal text, too unwilling to look beyond the law for explanations of law's coherence and meaning.

To my mind, all these positions express the uneasiness of legal scholars of whatever strand about their intellectual borrowings and politics. For all their differences, the post-modern, the critical legal scholar and the mainstreamer seem firmly within a post-realist tradition of legal scholarship. The realist problematic of law's simultaneous independence and bite 
continually reappears - as an anxiety about the status of the legal academic, or as a relationship between self-assertion and the invocation of clients. Their divergent works can best be understood in relationship to one another and they continue a single relationship to the extra-legal worlds of both intellection and political commitment. Indeed, I read the movement from post-realism to post-modernism as a series of recapitulative rotations constantly recycling a hesitancy about intellection and political commitment. Each phase seems to have worked out a homologous relationship to a politics and a world of ideas which is both projected beyond the law and imputed to it. Differences between phases have been marked both by academic generations struggling for acknowledgement in the vernacular and by differences in tone.

Thinking of these scholarly strands as rotations within a single tradition sheds light on both their distinctive contributions and their criticisms of one another. But this is too simple. It is not enough to see these strands of scholarship as continuations. They also mark real differences in the project of legal scholarship. Although there was a continuous relationship of mutual dependence and struggle between the post-realist mainstream and the original critic and between CLS and post-structuralism, there was also a destabilization which marked each stage as a departure. If these changes seem most dramatically changes in tone and emphasis, we should come to read tonal shifts as significant departures. At least in part because changes in tone signal changes in voice, identity and self.

The key to this second reading is to see each rotation, each repetition and tonal change within legal scholarship as a collapse of the scholarly voice which takes advantage of the previous strand's hidden awareness of the impossibility of its own project. Thus, the CLS scholar departed from the mainstream precisely by emphasizing political and intellectual voices present but hidden within mainstream work. The post-modern departs from CLS scholarship precisely because he takes the CLS scholar up on his doubts. In a final spin, the post-modern might be read to comment on the absurdity of his own enterprise even as he reads the nuance of the law with mainstream gentility.

Take the most typical post-modern law review article. It begins with a critical and summary introduction - locating the author and the reader politically and intellectually by invocation of some post-structuralist text and some client group. It then develops a model - usually a mega-model, aping the relationship between scholarly modes of understanding and doctrinal patterns - and elaborates it through a body of theoretical and doctrinal work. This modeled instability develops a polyphonous theme which ends, somewhat incongruously, where it began, with an invocation, perhaps somewhat problematized, of new voices, new forms of social life and new scholarships. Thus, the post-modern scholastic product looks very much like the product of the mainstream or CLS scholar. It is no wonder that it's invocation of post-structuralist philosophy seems hackneyed to those who are unaware of its relationship to mainstream and CLS work. The form of the postmodern legal text seems to undermine its reliance upon post-structuralism just as the 
invocation of post-structuralism seems to those within the legal academy to undercut the post-modern's participation in the forms of legal culture.

If we read post-modern legal scholarship as a rotation within the legal academy - as a departure, but also as a continuation of the problematic of contemporary legal scholarship, we might give the post-modern credit for a certain irony about its neo-classical imitation to be mocking the impossibility of both the analysis and the political invocation which it asserts. After all, calling for "face to face politics" or for a liberation of the "voice of women" in the full-dress regalia of a law review article, festooned with citations and the tone of edited clarity, has got to suggest its own impossibility.

Such a reading would emphasize that the post-modern legal text is situated in legal scholarship - responding to the demands of legal academia as it comments upon them and would credit the comment as much as the response. It would see a homology among the uneasiness and necessity of theory and politics for the mainstream, for CLS and for post-modern legal scholars. Far from excoriating the post-modern for his participation in the vernacular of a destabilized profession, such a reading would give the post-modern credit for recognizing the complexly ironic nature of contemporary legal teaching. In their teaching and writing the post-modern legal scholar, like his predecessors, constantly seeks the high ground of his profession - a high ground of intellection, of skepticism about ideas, of political commitment, of cynicism about politics - rotating through the positions of the mainstream and the CLS legal teacher or author with both some combination of violent abandon and careful finesse. This rotation would be read both as just one more turn of the wheel and as indicating, at least between the lines, a new project and voice for the legal scholar - one which upends, restates, recapitulates, and refuses as it continues the uneasy tradition of post-realist legal scholarship. 